\title{
Смягчение
}

\section{монетарной политики и структурные изменения в российской экономике}

А.А. БАЛАБИН, кандидат экономических наук, Институт экономики и организации промышленного производства СО РАН, Новосибирский государственный технический университет. E-mail: balabin-a-a@mail.ru

Обсуждаются проблемы влияния монетарной политики на изменение структуры кредитования экономики. Анализируется влияние ключевой ставки Банка России на структуру кредитования отраслей в 2007-2015 гг. Показано, что изменение ключевой ставки в последние годы почти не влияло на доли отраслей в кредитном портфеле банков, в то время как динамика индикативной рыночной ставки межбанковского кредитования (RUONIA) оказывала воздействие с определенным временным лагом. Даны оценки такого влияния по ряду крупных отраслей. Сделан вывод, что общее смягчение кредитно-денежной политики Центрального банка, не согласованное с активными целенаправленными действиями Правительства, в современных условиях не приведёт к сбалансированному и устойчивому росту реального сектора российской экономики. Ключевые слова: денежно-кредитная политика, количественное смягчение,

Б. Бернанке, М. Фридман, Центральный банк, ставка рефинансирования, ключевая ставка Банка России, RUONIA, структура кредитного портфеля банков

«Если понадобится, мы будем разбрасывать доллары с вертолета»

Многие политические и общественные деятели, известные экономисты и промышленники видят быстрое решение задачи реиндустриализации страны и её выхода на положительные темпы экономического роста в смягчении денежно-кредитной политики, в насыщении экономики денежными средствами за счет эмиссии, облегчения доступа к дешевым кредитным ресурсам. Так, Столыпинский клуб призывает реализовать количественное смягчение в России, начав «целевую» денежную эмиссию для осуществления инвестиционных проектов [1]. Неоднократно писал о необходимости изменения монетарной политики и журнал «ЭКО» (см., например [2-4]).

Дело, казалось бы, за малым. Достаточно Совету директоров Банка России проголосовать за снижение ставки рефинансирования, и/или за массовый выкуп неких активов, и вот - получите 
«дешевые» деньги! И Банку России это почти ничего не стоит, все полномочия у него уже есть. Казалось бы, и опыт развитых зарубежных стран, в том числе США, говорит о том же. «Какие молодцы эти американцы, вовремя в кризис 2007 г. пошли на решительное снижение ставок кредитования ФРС, на включение печатного станка, на количественное смягчение - и вытащили экономику!».

Известная фраза, приписываемая главе Федеральной резервной системы (ФРС) США и вынесенная в эпиграф данной статьи, будто бы создана для подтверждения этих мыслей. Однако высказываются и определенные сомнения в высокой эффективности программ количественного смягчения и их роли в ускорении роста экономики (см, например [5]). Так ли это просто - насытить экономику деньгами, чтобы она заработала в нужном направлении, не порождая при этом инфляцию?

\section{История одной цитаты}

Если верить ссылкам в Интернете, известная фраза о разбрасывании денег с вертолета вроде бы принадлежит Бену Бернанке, председателю совета управляющих ФРС в 2006-2014 гг. (за эти слова он и получил свое прозвище - «Бен-Вертолет»). Однако когда и по какому случаю он их произнес? Как мог выпускник Гарвардского университета, получивший $\mathrm{PhD}$ in Ecomics в Maccaчусетском технологическом институте, и преподаватель Стэнфордского университета, находясь на важном государственном посту, давать столь популистские обещания?

Википедия [6] туманно указывает, что Бернанке только процитировал Милтона Фридмана, основателя чикагской школы монетаризма и лауреата Нобелевской премии по экономике 1976 г., полученной «за достижения в области анализа потребления, истории денежного обращения и разработки монетарной теории, а также за практический показ сложности политики экономической стабилизации» [7]. И хотя М. Фридман широко известен своими образными высказываниями, как-то несерьёзно для выдающегося ученого выглядит рекомендация пускать деньги по ветру.

Обратимся к первоисточникам. Упоминание о «разбрасывании денег с вертолета» содержится в первом официальном выступлении Бена Бернанке в качестве члена совета управляющих ФРС 21 ноября 2002 г., посвященном теме дефляции [8]. Насколько нам известно, эта речь пока не издана на русском языке, поэтому позволим себе обширную цитату (уточняющие слова в квадратных скобках добавлены мной. А.Б.). «Каждый из вариантов [денежно-кредитной] политики, которые я обсуждал ранее, включает в себя только самостоятельные действия ФРС. На практике эффективность антидефляционной политики может быть значительно повышена путем сотрудничества между денежно-кредитными и фискальными органами. Например, всеобъемлющее снижение налогов ${ }^{1}$, совмещенное с программой [ФРС] по выкупу [активов] на открытом рынке с целью ослабить любые тенденции, приводящие к увеличению процентных ставок, почти наверняка будет эффективным стимулом для роста потребления, и, следовательно, цен. Даже если домохозяйства не станут увеличивать потребление, а вместо этого решат изменить свои накопления, используя избыточные денежные средства для приобретения реальных и финансовых активов, это приведет к увеличению стоимости активов, снижению стоимости капитала и улучшит показатели [бухгалтерских] балансов потенциальных заемщиков. Поддержанное денежной эмиссией всеобъемлющее снижение налогов, по существу, эквивалентно знаменитому “разбрасыванию денег с вертолета" Милтона Фридмана.

Конечно, вместо снижения налогов или увеличения трансфертов Правительство [США] может увеличить текущие расходы на товары и услуги или даже приобретать существующие реальные или финансовые активы. Если Казначейство [США] занимает в долг для последующей покупки частных активов, а ФРС затем приобретает равное количество долгов самого Казначейства, эмитируя деньги, вся операция будет экономическим эквивалентом прямых операций ФРС на открытом рынке по [приобретению] частных активов».

Из приведенной цитаты следует, что Бернанке говорил о возможности согласования действий между ФРС и Правительством США, которые в целях борьбы с дефляцией

${ }^{1}$ В оригинале broad-based taxe cut - имеется в виду не величина сокращения налогов, а именно широта, всеобщий охват снижением налогов всех экономических субъектов 
одновременно, каждый своими методами, пытаются увеличить денежное предложение и стимулировать текущее потребление. А действие этого сложного сочетания взаимодополняющих методов в совокупности напоминает эффект, описанный в некоем хрестоматийном примере из трудов Милтона Фридмана. Но, к сожалению, «широкая общественность» (как зарубежная, так и российская) уловила в академической речи только парутройку слов о разбрасывании денег.

Разберем пример Фридмана, о котором упоминает Бернанке. Он впервые был приведен в книге [9], а в переводе на русский язык его можно найти в [10, гл. 2]. В самом начале главы Фридман отмечает, что теория денег строится им в достаточно общей форме, на примере чрезвычайно упрощенного гипотетического общества, в котором главенствующие принципы денежного обращения предстают наиболее четко. Таким образом, приведенный им далее пример носит абстрактный, сугубо учебнотеоретический характер.

В придуманном Фридманом гипотетическом обществе все деньги представляют собой листочки бумаги с надписью «один доллар», а их количество составляет 1000 ед. Руководствуясь двумя мотивами (необходимостью каждодневного приобретения благ, при этом имея в виду страховку от возможных в будущем неожиданностей), каждый индивид предпочитает держать определенный запас денег, который Фридман эмпирически определяет в размере 1/10 годового дохода. То есть, если годовой доход общества составляет 10000 долл., для обеспечения нормального (стационарного) обмена товарами и услугами долларовым билетикам достаточно совершать 10 оборотов в год.

Далее автор проводит мысленный эксперимент - однократное скачкообразное увеличение номинального количества денег. «Предположим, - пишет он, - что однажды над нашим гипотетическим обществом появился вертолет и сбросил в виде тех самых бумажных билетиков еще одну тысячу долларов, которые, естественно, тут же были подобраны. Каждый из подобравших свою долю билетов уверен (это - наше предположение), что случившееся - событие уникальное и никогда более не повторится. Допустим, кроме того, что каждому из индивидов удалось подобрать ровно столько же билетов, сколько у него было до этого “своих", так что его запас наличности увеличился вдвое. Если бы каждый из них решил придержать свой избыток наличности, то ничего больше и не произошло бы. Сохранились бы цены, и годовой доход общества составлял все те же 10000 долларов».

Однако не такова природа людей. Убеждение, что событие уникально, приводит к тому, что каждый индивид пожелает вернуться к своему прежнему состоянию, повысив свое потребление и снижая запас наличности, пока последний не достигнет прежнего уровня. «Нетрудно предвидеть финал. Волна попыток истратить больше денег, чем получено, будет постепенно затухать, оставляя после себя след в виде растущей цены товаров и услуг. Добавленные листки бумаги не изменяют ни одного из условий в обществе. Они не делают доступными какие-либо новые, дополнительные объемы продукции, не изменяют вкусов и предпочтений, а также номинальную или фактическую скорость обращения. В результате, когда наступит равновесие, номинальный доход будет составлять уже 20000 долларов, вместо 10000 , при том же в точности, что и прежде, потоке реальных товаров и услуг».

Приводя пример, Фридман и не думал (как полагают сегодня некоторые) рекомендовать данный способ для стимулирования роста или изменения структуры экономики. Наоборот, он демонстрировал, что в результате «равномерного разбрасывания» денег никаких изменений в реальном секторе экономики не произойдет.

Поэтому Бернанке, вводя в свою речь скрытую ссылку на учебный пример М. Фридмана, имел в виду, что чисто монетарные совместные действия правительства и центрального банка (широкое снижение налогов плюс денежная эмиссия) быстро приведут к повышению уровня цен, не влияя при этом на реальные результаты функционирования экономики. Напомним, что доклад Бернанке был посвящен как раз методам борьбы с дефляцией.

Жаль только, что выводы теории не всегда могут быть услышаны и поняты. Вот что написал впоследствии Бернанке по поводу своего выступления ([11. Р. 64]): «Речь о дефляции обременила меня прозвищем “Бен Вертолет”. В обсуждении 
гипотетических возможностей в сражении с дефляцией я собирался упомянуть крайнюю тактику - всеобъемлющее снижение налогов, объединенное с эмиссией денег центральным банком, чтобы финансировать это снижение. Милтон Фридман назвал этот подход "разбрасыванием денег с вертолета". Дейв Скидмор, сотрудник по связям со СМИ, посоветовал мне удалить из речи эту метафору с вертолетом. "Подобные вещи не подобает говорить персоне из центрального банка”, - сказал он мне. Я ответил: "Ведь каждый знает, что об этом говорил Милтон Фридман”. Как оказалось, многие из трейдеров² с Уолл-Стрит, очевидно, не слишком углублялись в творчество Милтона».

Судя по многим текстам в русскоязычной части Интернета, российские «трейдеры» и «аналитики» мало чем отличаются от своих западных коллег.

\section{От теории к практике}

При знакомстве с взглядами некоторых российских сторонников количественного смягчения (особенно из среды собственников и директоров компаний реального сектора экономики) ощущается определенный дисбаланс в обосновании ими своих позиций. При подробном и четком знании потребностей развития своего предприятия и отрасли предложения в области денежно-кредитной политики сводятся к самым общим формулировкам о необходимости «снижения ставок Банка России», «насыщения экономики денежными средствами», «увеличения денежной массы», «повышения доступности кредитов» и т. п.

Иначе говоря, Банк России призывают в срочном порядке поднять свой вертолет и заняться «разбрасыванием денег». Конечно, есть и нюансы: крупные компании хотели бы, чтобы «денежный дождь» пролился на них, а защитники малого и среднего бизнеса, считая, что крупные компании и так находятся в привилегированном положении, предлагают

\footnotetext{
${ }^{2}$ В оригинале сказано более точно «bond traders» - «торговцы облигациями». Однако из контекста следует, что ирония Бернанке направлена и на рядовых работников, и на аналитиков, и на руководителей компаний, и на одиночек, занимающихся спекулятивной торговлей ценными бумагами. Вся эта разношерстная публика впоследствии была правдиво изображена в художественных фильмах «Волк с Уолл-стрит» (2013) и «Игра на понижение» (2015).
}

стимулировать именно их бизнес. Того же требуют инициаторы инвестиционных проектов, инноваторы и т. д. Но источник, как правило, один: снижение налогов и/или денежная эмиссия Банка России. Конечно, все понимают, что напрямую делать эмиссию Банку России запрещают законы ${ }^{3}$, поэтому он должен «помочь» госбанкам, а те обратят свое высокое внимание на бенефициаров. Финал применения этого простого рецепта описан в учебном примере М. Фридмана.

Перед российской экономикой стоит важнейшая задача реиндустриализации - переход от простой добычи природных ресурсов к всё более полной и эффективной их переработке, к производству (там, где это целесообразно) конкурентоспособных продуктов отечественного производства.

На первый взгляд кажется, что чем ниже ставка рефинансирования, тем доступнее кредиты, и тем более привлекательными для кредитования становятся заёмщики, не имеющие высокой рентабельности (например, обрабатывающие отрасли промышленности) или несущие большие риски (например, инновационные производства).

Попробуем проверить это, сопоставив динамику ключевой ставки Банка России и изменение структуры кредитования отраслей российской экономики в прошлые годы (см. таблицу).

Используемый в таблице термин «ключевая ставка Банка России» (обозначающий минимальную процентную ставку по операциям «репо» Банка России с коммерческими банками в рублях на аукционной основе на срок семь дней) был введен Банком России только в сентябре 2013 г., однако сами такие операции появились еще с 2003 г., что позволяет нам дополнить динамический ряд кредитных ставок более ранними датами. Мы сознательно не обсуждаем вопрос о влиянии на кредитование ставки рефинансирования Банка России, поскольку её формирование долгое время носило явно нерыночный характер. С начала 2016 г. Банк России попросту приравнял ставку рефинансирования к ключевой.

\footnotetext{
${ }^{3}$ Мы имеем в виду не только и не столько юридические законы, которые легко «доработать в нужную сторону» на заседаниях Федерального собрания, а в первую очередь законы рыночной экономики.
} 
Отраслевая структура кредитного портфеля российских банков и ставки кредитования, \%

\begin{tabular}{|c|c|c|c|c|c|c|c|c|c|c|c|}
\hline \multirow[b]{2}{*}{ Дата } & \multicolumn{9}{|c|}{$\begin{array}{c}\text { Доля вида деятельности в общей задолженности по кредитам } \\
\text { юридических лиц и индивидуальных предпринимателей, \% }\end{array}$} & \multirow[b]{2}{*}{ 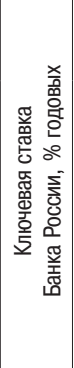 } & \multirow{2}{*}{ 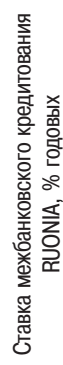 } \\
\hline & 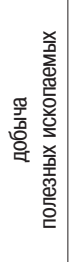 & 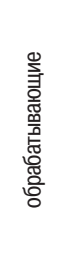 & 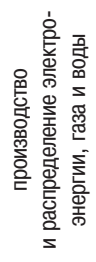 & 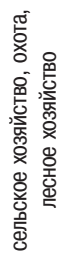 & 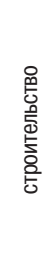 & 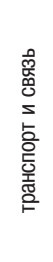 & 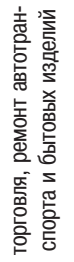 & 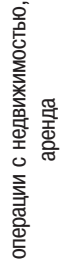 & 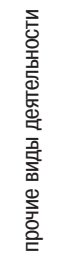 & & \\
\hline 01.07.2007 & 3,0 & 17,6 & 3,0 & 6,5 & 7,8 & 4,7 & 28,4 & 5,5 & 23,6 & 6,75 & - \\
\hline 01.01 .2008 & 4,3 & 18,8 & 2,3 & 5,2 & 8,4 & 5,1 & 25,1 & 7,8 & 23,0 & 6,75 & - \\
\hline 01.07 .2008 & 3,6 & 19,4 & 2,2 & 5,6 & 9,0 & 5,1 & 25,2 & 7,8 & 22,0 & 7,25 & - \\
\hline 01.01 .2009 & 4,4 & 19,4 & 2,5 & 5,7 & 8,2 & 5,9 & 23,4 & 8,7 & 21,8 & 9,50 & - \\
\hline 01.07.2009 & 5,3 & 19,6 & 2,5 & 5,7 & 8,5 & 5,4 & 24,0 & 11,1 & 17,8 & 9,00 & - \\
\hline 01.01 .2010 & 5,3 & 20,1 & 3,1 & 6,3 & 8,8 & 4,6 & 23,4 & 11,3 & 17,1 & 6,00 & 2,98 \\
\hline 01.07 .2010 & 5,2 & 20,7 & 3,2 & 6,6 & 9,2 & 4,5 & 22,1 & 11,9 & 16,5 & 5,00 & 2,01 \\
\hline 01.01 .2011 & 4,7 & 20,6 & 3,4 & 6,7 & 8,6 & 5,1 & 21,8 & 11,6 & 17,5 & 5,25 & 2,90 \\
\hline 01.07 .2011 & 4,3 & 19,7 & 3,3 & 7,0 & 8,8 & 5,8 & 21,6 & 12,0 & 17,4 & 5,50 & 3,70 \\
\hline 01.01 .2012 & 3,9 & 20,1 & 3,7 & 6,6 & 8,2 & 7,1 & 20,1 & 12,9 & 17,4 & 5,25 & 4,64 \\
\hline 01.07.2012 & 4,3 & 19,8 & 3,8 & 6,6 & 8,4 & 7,2 & 20,4 & 13,7 & 15,8 & 5,25 & 5,54 \\
\hline 01.01 .2013 & 4,5 & 19,8 & 3,8 & 6,5 & 8,3 & 7,6 & 20,2 & 13,8 & 15,5 & 5,50 & 5,33 \\
\hline 01.07.2013 & 4,4 & 19,4 & 3,5 & 6,6 & 8,1 & 6,6 & 20,6 & 14,8 & 16,0 & 5,50 & 6,35 \\
\hline 01.01 .2014 & 4,4 & 20,0 & 3,6 & 6,4 & 8,0 & 6,4 & 19,8 & 15,2 & 16,2 & 5,50 & 6,24 \\
\hline 01.07.2014 & 4,8 & 20,7 & 3,8 & 6,1 & 7,9 & 6,3 & 19,2 & 14,5 & 16,7 & 7,50 & 8,17 \\
\hline 01.01 .2015 & 6,2 & 22,0 & 3,5 & 5,3 & 8,2 & 6,2 & 18,0 & 14,7 & 15,9 & 17,00 & 17,39 \\
\hline 01.07.2015 & 6,3 & 22,0 & 3,6 & 5,5 & 7,9 & 5,9 & 17,4 & 15,4 & 16,0 & 11,50 & 12,13 \\
\hline 01.01 .2016 & 7,0 & 23,4 & 3,5 & 5,1 & 7,0 & 5,7 & 14,6 & 16,3 & 17,4 & 11,00 & 10,52 \\
\hline
\end{tabular}

Источники:

Доли отдельных видов деятельности в кредитном портфеле (ранее 01.04.2009 г.) рассчитаны по данным Банка России: ежеквартальный «Бюллетень банковской статистики - региональное приложение» (до 01.01.2009), "Сведения о размещенных и привлеченных средствах». URL: http://www.cbr.ru/statistics/? Prtld=sors (начиная с 01.07.2009 г.).

Ключевая ставка Банка России - URL: http://www.cbr.ru/hd_base/default. aspx?prtid=repo_proc\&pid=idkp_br\&sid=ITM_15890.

Ставка межбанковского кредитования RUONNIA - URL: http://www.ruonia.ru/archive.html (если дата приходилась на выходной или праздничный день, указано значение ставки в ближайший рабочий день).
Ставка межбанковского кредитования RUONIA (Ruble Overnight Index Average) - усредненная ставка рублевых кредитов (депозитов) на условиях overnight стандартным заемщикам из числа трех десятков российских банков с минимальным кредитным риском. RUONIA рассчитывается Банком России ${ }^{4}$ с января 2010 г. и учитывает только фактически состоявшиеся рыночные сделки внутри группы банков. Она не используется Банком России для целей регулирования операций рефинансирования, т. е. носит индикативный характер 5 .

Первое, что следует отметить, - высокая стабильность отраслевой структуры кредитования российской экономики. На протяжении без малого десяти лет, несмотря на спады и подъемы, доли отдельных направлений кредитования эволюционировали довольно медленно. При этом ставки кредитования менялись более существенно, как в большую, так и в меньшую сторону. Это уже само по себе говорит об их слабом влиянии на отраслевую структуру кредитования.

Так, в 2008-2010 гг. наблюдался систематический (хотя и медленный) рост доли обрабатывающих производств в кредитном портфеле. В то время ключевая ставка сначала росла с 6,75 до 9,5\%, затем снижалась до 5\% годовых, суммарная же доля торговли, операций с недвижимостью и прочих отраслей медленно уменьшалась с 57,5 до 50,4\%. До настоящего времени около половины кредитных ресурсов вкладывается в сферу обращения.

Отметим рост доли добычи полезных ископаемых (с 5 до 7\%) и обрабатывающих производств (с 20 до 23\%) начиная с 2015 г., при резком росте ключевой ставки. В данном случае изменения были вызваны скорее политическими причинами (затруднения в получении кредитов добывающими компаниями

4 Методика расчета разработана Национальной фондовой acсоциацией. URL: http://www.ruonia.ru/methodology.html.

${ }^{5}$ Небезинтересно, что ФРС США для целей регулирования своих операций рефинансирования использует в качестве отправной точки именно ставку межбанковских операций “овернайт» (так называемую целевую ставку федеральных фондов, federal funds target rate). А американский аналог RUONIA обозначается похожим термином federal funds rate и прямого отношения к операциям ФРС не имеет; это усредненная процентная ставка рыночного кредитования одного коммерческого банка другим. Сходство терминов порождает иногда весьма забавную путаницу в средствах массовой информации. 
за рубежом из-за действия санкций, увеличение заказов оборонного назначения и связанного с ним технического перевооружения оборонных предприятий и их смежников) $)^{6}$.

Для исследования влияния кредитных ставок на отраслевую структуру кредитования нужно учесть, что изменение ключевой ставки не может действовать мгновенно. Поскольку сроки кредитования составляют не менее нескольких месяцев, структура кредитования будет меняться с лагом около полугода (а возможно и более), по мере погашения «старых» кредитов и замены их «новыми», выданными по другим процентным ставкам. В связи с этим нами был сделан расчет коэффициента корреляции Пирсона между величиной доли обрабатывающих производств и ключевой ставкой Банка России при разных предположениях о длительности этого лага. Если предположить, что ключевая ставка действует мгновенно (лаг равен нулю), корреляция составляет $+0,56$, если лаг составляет шесть месяцев, коэффициент будет равен $+0,57$, если год - то $+0,67$.

Таким образом, при любых предположениях о лаге статистическую связь между изменением структуры кредитования и ключевой ставки нельзя признать значимой. Иначе говоря, уменышение ключевой ставки (действуя подобно «равномерному разбрасыванию денег с вертолета») почти не влияет на структуру распределения кредитных ресурсов в пользу тех или иных видов деятельности.

Подтверждается это и данными опроса российских банков, проведенного в 2016 г. Ассоциацией региональных банков «Россия» [12]: 23\% опрошенных банков сообщили, что вообще не используют ключевую ставку Банка России в качестве ценового индикатора ни для депозитных, ни для кредитных ставок.

\footnotetext{
${ }^{6}$ Начало долгосрочного кредитования оборонных предприятий относится к 2011-2012 гг., когда была выработана схема, по которой четверка крупнейших финансовых организаций (Сбербанк, ВТБ, Газпромбанк и ВЭБ) кредитовали предприятия по ставке не выше $10 \%$ годовых под государственные гарантии в счет будущего финансирования гособоронзаказа. Только в 2017 г. предстоит погасить (или пролонгировать) таких кредитов на 319 млрд руб., в 2018 г. - на 470 млрд руб. [17], что составляет (оценочно) около 15-20\% объема гособоронзаказа на эти годы. Кроме того, получение “твердых» государственных заказов само по себе может положительно влиять на решение банка о кредитовании «кассовых разрывов» и/или предоставлении овердрафта предприятию.
}

Для сравнения мы провели аналогичный расчет корреляции между долями различных направлений кредитования и индикативной ставкой межбанковского кредитования RUONIA.

Коэффициенты корреляции этой ставки с долей обрабатывающих отраслей составили: $+0,67$ (при предположении об отсутствии лага), $+0,71$ (лаг в шесть месяцев), $+0,84$ (лаг в один год). Таким образом, можно признать наличие статистически значимой связи между изменением доли обрабатывающих отраслей в кредитном портфеле и произошедшими за год и более до этого изменениями рыночных межбанковских ставок «овернайт» ${ }^{7}$. Однако эта связь выглядит парадоксально для сторонников смягчения кредитно-денежной политики. Коэффициент корреляции положителен, т. е. чем выше были рыночные ставки кредитования, тем больше впоследствии росла доля обрабатывающих отраслей в кредитном портфеле банков.

В то же время (при том же предположении о годовом лаге) коэффициент корреляции между RUONIA и долей торговли равен $-0,93$, т. е. доля этого направления деятельности в кредитах была связана обратно пропорционально с изменением кредитной ставки. Иначе говоря, рост ставки RUONIA приводит в дальнейшем (с лагом в год) к снижению доли торговли в кредитном портфеле.

Можно сделать осторожный вывод о том, что снижение рыночных ставок кредитования оказывает противоположное воздействие на доли торговли и обрабатывающих производств в кредитном портфеле банков. В частности, снижение рыночных ставок кредитования с определенным лагом увеличивает долю торговли и в то же время снижает долю обрабатывающих производств.

Таким образом, первоначальная гипотеза о «прогрессивном» влиянии снижения общего уровня кредитных ставок на отраслевую структуру кредитования не подтверждается статистически.

Однако не стоит преувеличивать значение наших упрощенных расчетов: слишком коротки пока что временные ряды, слишком много действовало в рассматриваемый период

7 По данным статистики США, полные последствия новой кредитноденежной политики для объема выпуска проявляются лишь спустя 16-20 месяцев после её первоначального изменения [13. С. 678]. 
разнообразных факторов. Это просто повод задуматься над, казалось бы, очевидными истинами, и не искать простых решений для сложных вопросов.

Что касается сегодняшней финансовой ситуации, то выясняется, что, несмотря на некоторый избыток денежных средств, деньги всё равно «не хотят идти» на благие цели. Почти все опрошенные банки сообщили [12], что не испытывают в настоящее время проблем с ликвидностью, а 87\% ощущают даже её избыток. Однако это не является непосредственным поводом для увеличения кредитования реального сектора, что связывается с ухудшением финансового положения компаний (87\% опрошенных), и/или отсутствием спроса на кредиты (61\%). Лишь чуть более трети банков-респондентов считают, что росту мешают высокие процентные ставки.

Бывший ответственный работник Минфина, а ныне зампредседателя Внешэкономбанка А.Н. Клепач, выступая на Петербургском международном экономическом форуме, сказал: «Деньги есть, но они не работают. Кредиты предприятиям не растут - новые кредиты не открываются, только пролонгация или выбор уже открытых кредитных линий. Кредитование регионов тоже не растет, регионы закредитованы. Общее снижение процентной ставки не трансформируется в доступность кредитов для бизнеса и населения. Механизмы финансирования малого и среднего бизнеса не работают: кредиты таким предприятиям в 2015 г. сократились на 30\%, почти на триллион» (цит. по [14. С.36]). Значит, дело не в недостатке денежного предложения?

Нетрудно также понять, куда при дальнейшем смягчении кредитно-денежной политики, но при прежних рисках кредитования и имеющихся институтах развития, будут направляться «избыточные» деньги, накапливающиеся в настоящее время в российской банковской системе. Банки, имевшие задолженность перед Банком России и/или Минфином, нараставшую в 2014-2015 гг., будут погашать в первую очередь её [15]. При отсутствии задолженности деньги будут размещаться либо на депозитах в Банке России, либо вкладываться в новые выпуски ценных бумаг Минфина или Банка России, либо в лучшем случае - воспроизводить прежний неустойчивый, несбалансированный рост, увеличивая кредитование торговли и иных предприятий сферы обращения.

Об этом же говорит анализ практики количественного смягчения в зарубежных странах, где в последнее время наблюдается очень быстрый рост цен на рынке ценных бумаг, не соразмерный темпам изменения валового внутреннего продукта [5. С. 60]. Можно согласиться с Председателем Банка России Э.С. Набиуллиной [16], что в данных обстоятельствах требуется осторожная, умеренно-жесткая денежно-кредитная политика, сопровождающая (но ни в коем случае не опережающая) проведение реальных структурных реформ российской экономики.

Затруднительно использовать рычаги кредитно-денежной политики для изменения структуры российской экономики без соответствующих целенаправленных, соразмерных и решительных действий правительства. Ключевой вопрос состоит не в том, нужно или не нужно смягчать монетарную политику, а в том, для достижения каких целей и в чьих интересах её нужно смягчать. А на этот вопрос Банк России единолично не ответит. И уж тем более он не может и не должен отвечать «за развитие экономики» или «за обеспечение занятости».

Отметим, что в арсенале центральных банков (в том числе, что немаловажно, и у Банка России) уже имеются и используются более тонкие и селективно действующие методы монетарной политики, чем простое манипулирование ставкой рефинансирования. Однако их обсуждение уже выходит за пределы данной статьи.

\section{Литература}

1. Экономика роста. Доклад Столыпинского клуба. URL: http:// stolypinsky.club/economica-rosta

2. Аганбегян А. Г. Как преодолеть стагнацию и восстановить экономическое развитие // ЭКО. - 2016. - № 2. - С. 3-10.

3. Баранов А.О. Время не ждет: экономическая политика как инструмент преодоления рецессии в России //ЭКО. - 2016. № 4. - С. 5-23.

4. Масленников В.В. Влияние современной денежно-кредитной политики России на экономический рост//ЭКО. - 2015. - № 10. С. 153-166. 
5. Балабин А.А. Плоды количественного смягчения //ЭКО. 2016. - № 6. - С. 50-67.

6. Бернанке Бен // Википедия. [2016-2016]. Дата обновления: 07.04.2016. Цит. по: URL: http://ru.wikipedia.org/?oldid=77622301 (дата обращения: 02.07.2016).

7. Цит. по: URL: http://n-t.ru/nl/ek/friedman.htm (дата обращения: 02.07.2016).

8. Bernanke B. Deflation: Making Sure «lt» Doesn't Happen Here // Remarks by Governor Ben S. Bernanke before the National Economists Club, Washington, D.C., November 21, 2002. URL: https://www. federalreserve.gov/boarddocs/Speeches/2002/20021121/default.htm 9. Friedman $M$. The optimum quantity of money and other essays / Aldine Pub. Co. - Chicago, 1969.

10. Фридмен М. Количественная теория денег - М.: Эльф пресс, 1996. - $131 \mathrm{C}$.

11. Bernanke $B$. The Courage to Act: A Memoir of a Crisis and Its Aftermath / W. W. Norton \& Comp, 2015. - 624 p.

12. Кувшинова О. Боги не очень слушают банкиров//Ведомости. 2016. - 04 июля.

13. Абель Э., Бернанке Б. Макроэкономика. - М.: Питер, 2010.

14. Огородников Е. Жить без капитала нельзя//Эксперт. - 2016. № 25. - С. 34-37.

15. Биянова Н., Еремина А. У банков слишком много денег//Beдомости. - 2016. - 20 апр.

16. Выступление Председателя Банка России Эльвиры Набиуллиной на XXV Международном финансовом конгрессе 30.06.2016. URL: http://www.cbr.ru/Press/print.aspx?file=press_centre/Nabiullina_160630.htm\&pid=st\&sid=ITM_15798 